\title{
2 A \\ New Thiazolidine-Based Organocatalysts for Enantio- and Diastereoselective Aldol Reaction
}

\section{Caroline Gross Jacoby (IC), Raoní Scheibler Rambo (PG), Tiago Lima da Silva (PG), Paulo Henrique Schneider* (PQ)}

\author{
Instituto de Química, UFRGS - Av. Bento Gonçalves, 9500, Porto Alegre, RS, Brasil, 91501-970 \\ *paulos@iq.ufrgs.br
}

Keywords: organocatalysis, thiazolidine, asymmetric aldol

\section{INTRODUCTION}

Asymmetric organocatalysis is recognized as an efficient and versatile method for the stereoselective preparation of chiral compounds ${ }^{1,2}$. Over 300 reactions have been developed using organocatalyzed processes ${ }^{2}$. This strategy is attractive because in most cases the catalysts are nontoxic, readily available and stable. Another feature is that most reactions tolerate water and air $^{1,2}$.

In the present work, we describe the synthesis of new thiazolidine-based organocatalysts and their application in asymmetric direct aldol additions.

\section{RESULTS AND DISCUSSION}

Based on the organocatalysts recently developed by our group (1a-c) $)^{3}$, we synthesized new thiazolidinebased compounds (1d-f), in order to improve their catalytic activity and selectivity (Figure 1).

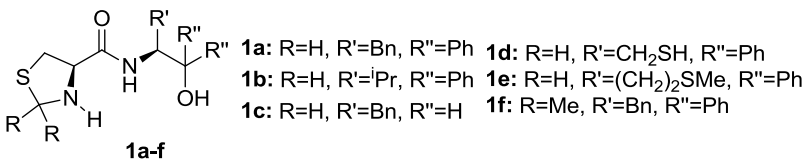

Figure 1. Thiazolidine-based organocatalysts 1a-f.

Initially, L-cysteine was cyclized with paraformaldehyde or propanone leading to the thiazolidines, which were protected with $\mathrm{Boc}_{2} \mathrm{O}$ to afford the fragments $3 \mathbf{a}-\mathbf{b}$.

The aminoalcohols 4a-c were obtained from $L$ aminoacid-Me-esters by double Grignard addition.

Finally, the reaction between thiazolidines $\mathbf{3} \mathbf{a}-\mathbf{b}$ and the aminoalcohols $4 a-c$, followed by removal of the Boc group, lead to the new organocatalysts 1d-f.

Scheme 1. Preparation of compounds 1d-f.

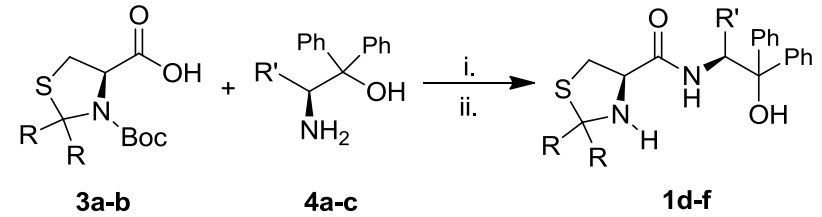

Reactions conditions: (i) CICOOEt, NMM, $\mathrm{CH}_{2} \mathrm{Cl}_{2}$, r.t., 24 h (75$85 \%$ ); (ii) $\mathrm{HCl}, \mathrm{AcOEt}, \mathrm{K}_{2} \mathrm{CO}_{3}$, DCM, r.t., $30 \mathrm{~min}(50-80 \%)$.
Compounds 1a-f were employed as catalysts in the asymmetric direct aldol addition between cyclic ketones and aromatic aldehydes.

Scheme 2. Asymmetric direct aldol reaction catalyzed by organocatalysts 1a-f.

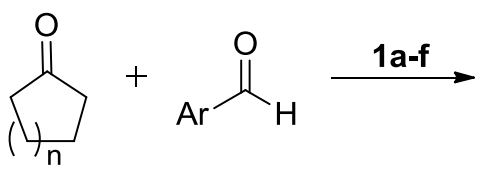<smiles>O=C1CCCC1[C@H](O)Br</smiles>

up to $99 \%$ e.e. $99 \%$ d.e.

The effect of temperature, catalyst loading, time and solvent were investigated. Using saturated aqueous media, the aldol adducts were obtained with excellent stereocontrol (up to $99 \%$ e.e. and $99 \%$ d.e.).

\section{CONCLUSION}

Three new organocatalysts derived from $L$ aminoacids were synthesized. The influence of electronic and steric characteristics of the compounds was explored and the catalytic system was optimized.

The results demonstrated that compound 1 a was the best catalyst and the aldol adducts were obtained in excellent enantiomeric and diastereomeric excesses.

\section{ACKNOWLEDGEMENTS}

The authors are grateful to UFRGS, CAPES, CNPq, INCT-CMN and FAPERGS for financial support.

\section{REFERENCES}

${ }^{1}$ Pelissier, H. Tetrahedron 2007, 38, 9267.

${ }^{2}$ MacMillan, D. W. C. Nature 2008, 455, 304.

${ }^{3}$ Rambo, R. S.; Schneider, P. H. Tetrahedron: Asymmetry. 2010, 21, 2254.

$15^{\text {th }}$ Brazilian Meeting on Organic Synthesis - $15^{\text {th }}$ BMOS - November 10-13, 2013 - Campos do Jordão, Brazil 